\title{
Effects of Lateral Velocity Heterogeneity Under the Nevada Test Site on Short-Period $P$ Wave Amplitudes and Travel Times
}

\author{
CHRISTOPHER S. LYNNES ${ }^{1}$ and THORNE LAY ${ }^{1}$
}

\begin{abstract}
Short-period teleseismic $P$ waves from the Nevada Test Site (NTS) show systematic variations in amplitudes and travel times, with low amplitudes corresponding to fast travel times, suggesting elastic focussing-defocussing effects. Also, the azimuthal amplitude and travel time patterns for events at the Pahute Mesa subsite are systematically different from those at the Yucca Flat subsite, indicating the presence of a near-source component in both the amplitude and travel-time variations. This component is isolated by removing the mean station pattern for all of NTS from the observations. A very-near-source component in the Pahute Mesa observations is also isolated by removing subsite station means from the measurements, whereas the Yucca Flat observations exhibited no coherent very-near-source component. These anomalies are back-projected through laterally homogeneous structure to form thin lens models at various depths. Travel-time delays are predicted from the amplitude variations using the equation for wavefront curvature. The long-wavelength components of the predicted and observed time delays correlate well at depths of $25 \mathrm{~km}$ for the very-near-source component under Pahute Mesa and $160 \mathrm{~km}$ for the regional component under NTS. The time delay surfaces predicted by the amplitudes at these depths are mapped into warped velocity discontinuities suitable for the calculation of synthetic seismograms using the Kirchhoff-Helmholtz integral formulation. Both the intersite (near-source) and intrasite (very-near-source) differences in amplitudes are qualitatively predicted very well, although the range of variation is somewhat underpredicted. This deficiency is likely due to the destructive interference of anomalies inherent in back-projection to a single layer.
\end{abstract}

Key words: $P$ wave amplitudes, focussing, three-dimensional wave propagation.

\section{Introduction}

Theoretically, an underground explosion should radiate compressional waves isotropically. However, several studies of short-period $P$ waves from explosions (e.g., LAY et al., 1984; BURGER et al., 1986) have indicated that amplitudes can have coherent variations with azimuth ranging over factors of 3 to $10(10-20 \mathrm{db})$. Such variations are important to understand because of the uncertainty they add to underground test size estimation. Furthermore, those variations can be extremely useful in investigating lateral variations in earth structure, particularly when

\footnotetext{
I Department of Geological Sciences, University of Michigan, Ann Arbor, MI 48109, U.S.A.
} 
examined in concert with travel-time data. Given sufficiently accurate earth models, it may be possible to correct the amplitude variations for propagational effects, thereby improving the accuracy of the size estimates.

In this study, we examine short-period $P$ wave amplitudes in conjunction with travel times from underground explosions at the Nevada Test Site (NTS). A previous analysis (LYNNES and LAY, 1988a) has established that low amplitudes correlate with fast travel times, implying that variations in velocity, rather than attenuation, are primarily responsible for the amplitude fluctuations. These amplitude variations are used in this study to derive laterally varying velocity structures, parameterized as warped velocity discontinuities that are as compatible as possible with the travel-time observations.

Underground explosions at NTS (Figure 1) provide a dense, well-located array of sources that offers an excellent site for such a study. Also, several travel-time studies have already found evidence for significant lateral heterogeneity in the crust and upper mantle beneath NTS (SPENCE, 1974; MiNSTER et al., 1981; TAYLOR, 1983), and the geology of the general area is replete with Cenozoic calderas, which might be expected to produce or be related to lateral velocity variations.

A few previous studies have predicted amplitude variations using models derived from travel-time data. THOMSON and GuBBINS (1982) calculated amplitudes for the Norwegian Seismic Array (NORSAR) using a smoothly varying structure obtained by a linear inversion of travel times. Although they found statistically significant correlations between predicted and observed amplitudes, the predicted amplitude range was much smaller than the observed range. CORMIER (1987) traced rays through TAYLOR's (1983) three-dimensional model of the lithosphere under NTS, producing amplitude variations for a Pahute Mesa explosion that were similar to the observed variations reported in LAY et al. (1984). On the other hand, LAY et al.

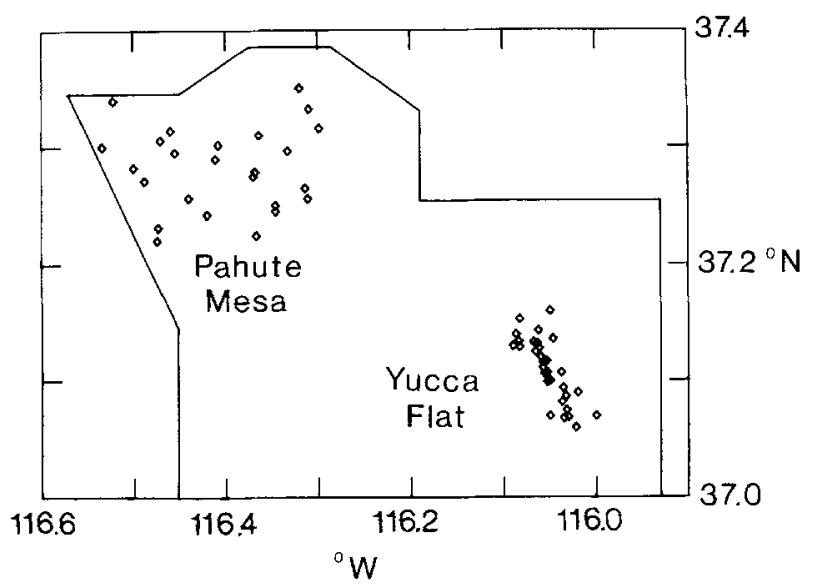

Figure 1

Map of the Nevada Test Site source array. 
(1986) traced rays through the structure derived by MINSTER et al. (1981) from travel times for the same area, finding almost no variation in amplitudes. The two travel-time inversions use overlapping data sets of teleseismic travel times, but differ in the parameterization of the model: Taylor's model extends to $100 \mathrm{~km}$ depth, and includes information from $P_{n}$ source terms, while MINSTER et al. invert for perturbations down to $150 \mathrm{~km}$ and employ an additional smoothing algorithm in the inversion. The result is that TAYLOR's (1983) model has velocity perturbations that are larger than in MINSTER et al.'s model by a factor of three and fluctuate more rapidly. The attendant differences in lateral velocity gradients between the two models have a drastic effect on the predicted amplitude variations.

Given the dependence of predicted amplitudes on the parameterization of the travel-time models, it would be desirable to obtain a velocity structure from the amplitudes themselves. However, due to the nonlinear relationship of amplitudes to velocity structure, such inversions have been few. HADDON and HUSEBYE (1978) projected amplitude variations onto surfaces at depths between 150 and $200 \mathrm{~km}$ below the NORSAR array, and used an equation describing wavefront curvature to predict travel-time variations due to an infinitely thin lens, obtaining a high correlation with observed travel-time residuals. THOMSON (1983) inverted amplitudes recorded at NORSAR for a smoothly varying structure using a raytracing formalism, obtaining fairly good amplitude predictions but only moderate correlations of predicted and observed travel times. Thus, amplitudes seem to contain information that is partially complementary to that in the travel times.

Another attempt to produce the amplitude variations at NTS is the forward modeling approach of SCOTT and HELMBERGER (1985), who assumed an upwarped Mohorovicic discontinuity. By calculating synthetic seismograms for arbitary structures using the Kirchhoff-Helmholtz integral technique, they obtained amplitude variations as high as a factor of $2.5(8 \mathrm{db})$. Thus, this type of model shows some promise of explaining the amplitude anomalies from NTS explosions. However, it would be preferable to invert the amplitudes themselves for a candidate structure, rather than using ad hoc models.

Our procedure for imaging the velocity structure uses the thin lens projection to construct a model of a warped velocity discontinuity. Travel-time delays are computed from the equation of wavefront curvature as in HADDON and HUSEBYE (1978), and are then mapped into topography of a velocity discontinuity. This structure is then tested by computing synthetic seismograms using the KirchhoffHelmholtz integral method.

\section{Observed Travel Time and Amplitude Variations}

Over $2000 P$ wave $a b$ (first-peak-to-first-trough) amplitudes and travel times were measured from waveforms for 57 explosions at the Pahute Mesa and Yucca Flat test sites in Nevada (Figure 1). The receivers were short-period WWSSN and 
Canadian Seismic Network seismographs at distances of $25^{\circ}-95^{\circ}$. A complete statistical analysis of this data set is presented in LYNNES and LAY (1988a). The amplitude data set actually consists of $\Delta m_{b}$ values (i.e., deviations from the explosion mean). The station average values for Pahute Mesa $\left({ }_{\mathrm{PM}} S_{i}\right)$ and Yucca Flat $\left({ }_{\mathrm{YF}} S_{i}\right)$ are presented on equal-area diagrams in Figure 2. The two test sites have similar patterns for both measurements, suggesting that both the amplitude and travel-time patterns have a component related to deep path and/or near-receiver effects. However, the deviations from the mean for Pahute Mesa are systematically and coherently larger in each case. These intersite differences indicate a near-source component. In an attempt to minimize the deep path and near-receiver effects, the mean of the average station anomalies $\left.\left({ }_{\mathrm{PM}} S_{i}+{ }_{\mathrm{YF}} S_{i}\right] / 2={ }_{\mathrm{NTS}} S_{i}\right)$ for the two test
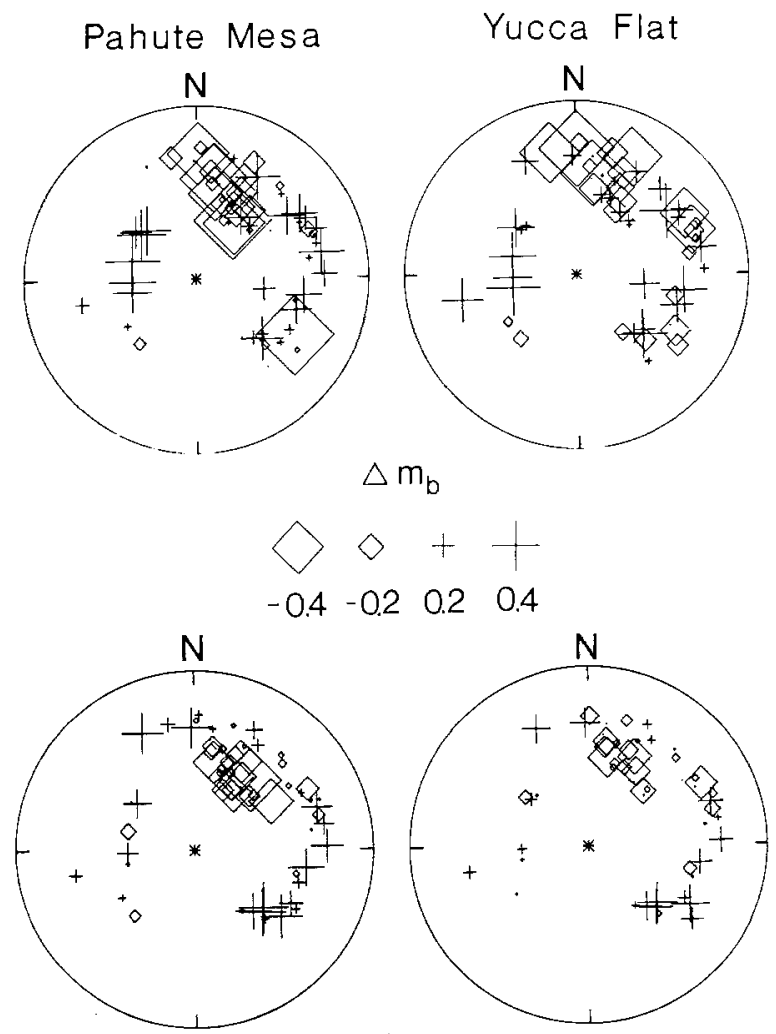

$\Delta t, s$

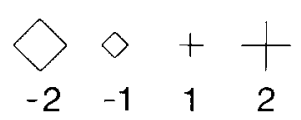

Figure 2

Equal-area plots of station mean travel time and magnitude anomalies for the Pahute Mesa and Yucca Flat test sites. The rim corresponds to a takeoff angle of $22.5^{\circ}$ in a velocity of $3.5 \mathrm{~km} / \mathrm{s}$. 
sites was removed from the individual travel time and amplitude measurements. This should provide a fairly conservative estimate of the near-source component of amplitude and travel-time variation, although there is some potential for effects unique to one subsite to be folded into the data for the other. An independent test of this assumption can be provided in the case of the amplitude data by comparing the root-mean-square of the first five seconds $\left(\mathrm{RMS}^{0-5}\right)$, which represents the direct arrival, to the root-mean-square of the next ten seconds ( $\mathrm{RMS}^{5-15}$ ), which represents the early coda. The early coda should average out much of the near-source focussing-defocussing effects, thus providing a reference for the direct arrival amplitudes. The station mean values of $\log \left(\mathrm{RMS}^{0-5} / \mathrm{RMS}^{5-15}\right)$ are plotted in Figure 3 , along with the individual station mean magnitude anomalies with the regional
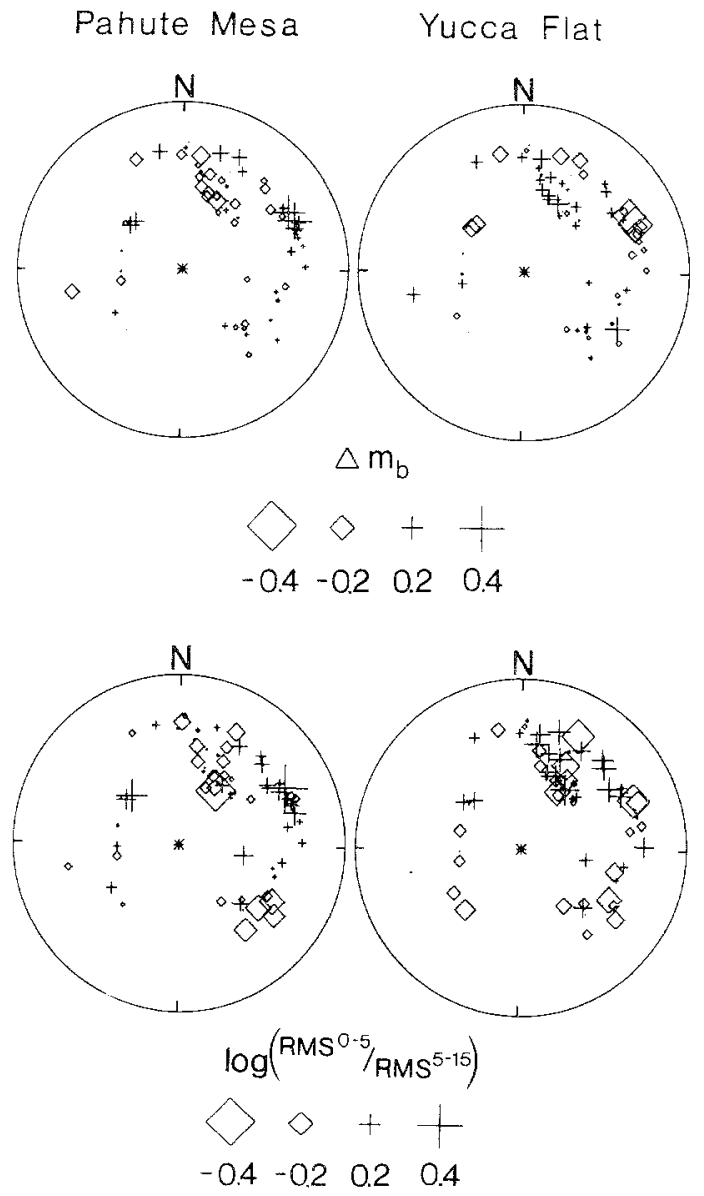

Figure 3

Equal-area plots of station mean magnitude anomalies, with NTS station means removed, are plotted above station mean values of $\log \left(\mathrm{RMS}^{0-5} / \mathrm{RMS}^{5-15}\right)$. 
means removed ( ${ }_{\mathrm{PM}} S_{i}-{ }_{\mathrm{NTS}} S_{i}$ and $\left.{ }_{\mathrm{YF}} S_{i}-{ }_{\mathrm{NTS}} S_{i}\right)$. The patterns for Pahute Mesa are strikingly similar in range and sense. The resemblance of the Yucca Flat patterns is somewhat less, probably due to the complex very-near-source structure (LYNNES and LAY, 1988b).

Another important correlation is that between travel times and amplitudes. Fast travel times (negative residuals) generally correspond to low amplitudes, e.g., in the north-northeast of the Pahute Mesa pattern. This type of correlation is generally an indication of focussing-defocussing effects (e.g., Chang and von SEgGern, 1980; BUTLER, 1983). Thermally activated variations in attenuation, on the other hand, would predict a correlation of slow times with low amplitudes (cf., BUTLER, 1984).

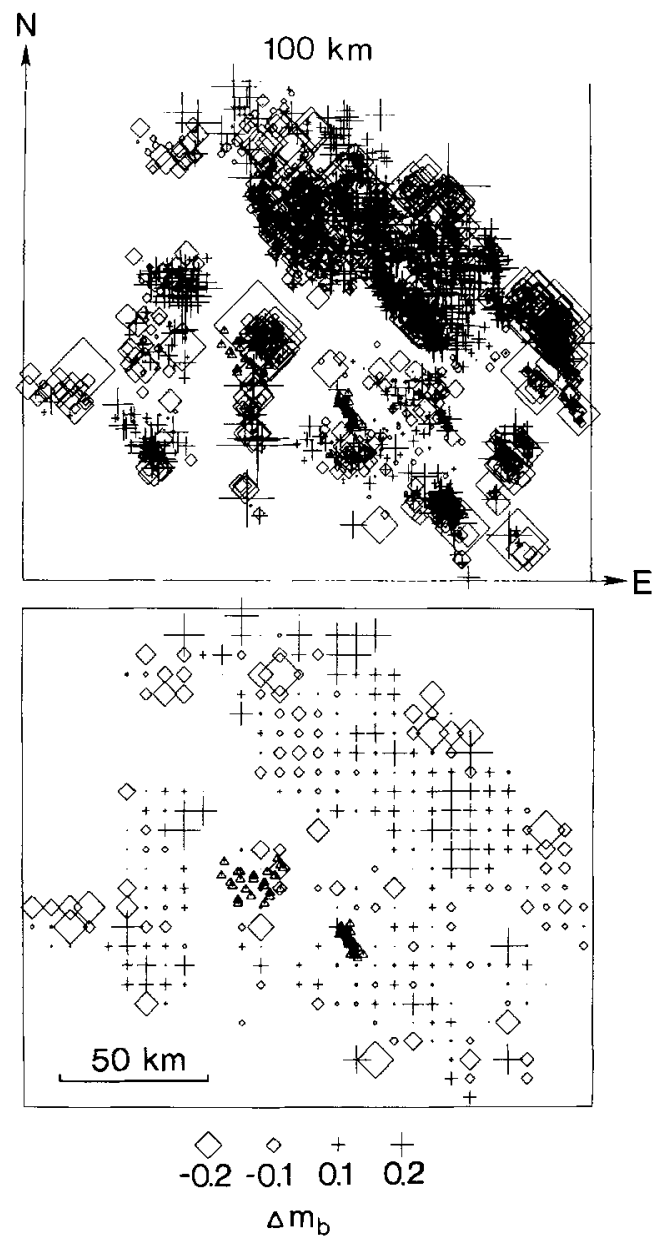

Figure 4

Example of back-projection procedure. Magnitude anomalies, with NTS station means removed, are projected through laterally homogeneous structure to a depth of $100 \mathrm{~km}$ (a). The surface is gridded and the values in each grid square are averaged to provide a bin-averaged projection (b). The triangles indicate the positions of the sources. 


\section{Back Projections of Amplitudes and Travel Times}

The procedure for imaging thin lens structures that might produce the observed amplitude and travel-time patterns is a simple back-projection of the teleseismic anomalies. The rays are traced through a laterally homogeneous structure, and the appropriate anomaly is projected to the point below the source area where the ray reaches a given depth (Figure 4a), in this case $100 \mathrm{~km}$. The structure used is the reference model for NTS used by TAYLOR (1983) for three-dimensional travel-time inversion, on top of the T7 model of BURDICK and HELMBERGER (1978). The projection surface is then gridded, and the values within each grid square are averaged to obtain a bin-averaged projection (Figure $4 \mathrm{~b}$ ). The bin-averaged projections for depths of 35, 100 and $160 \mathrm{~km}$ are shown in Figure 5 for both the amplitude
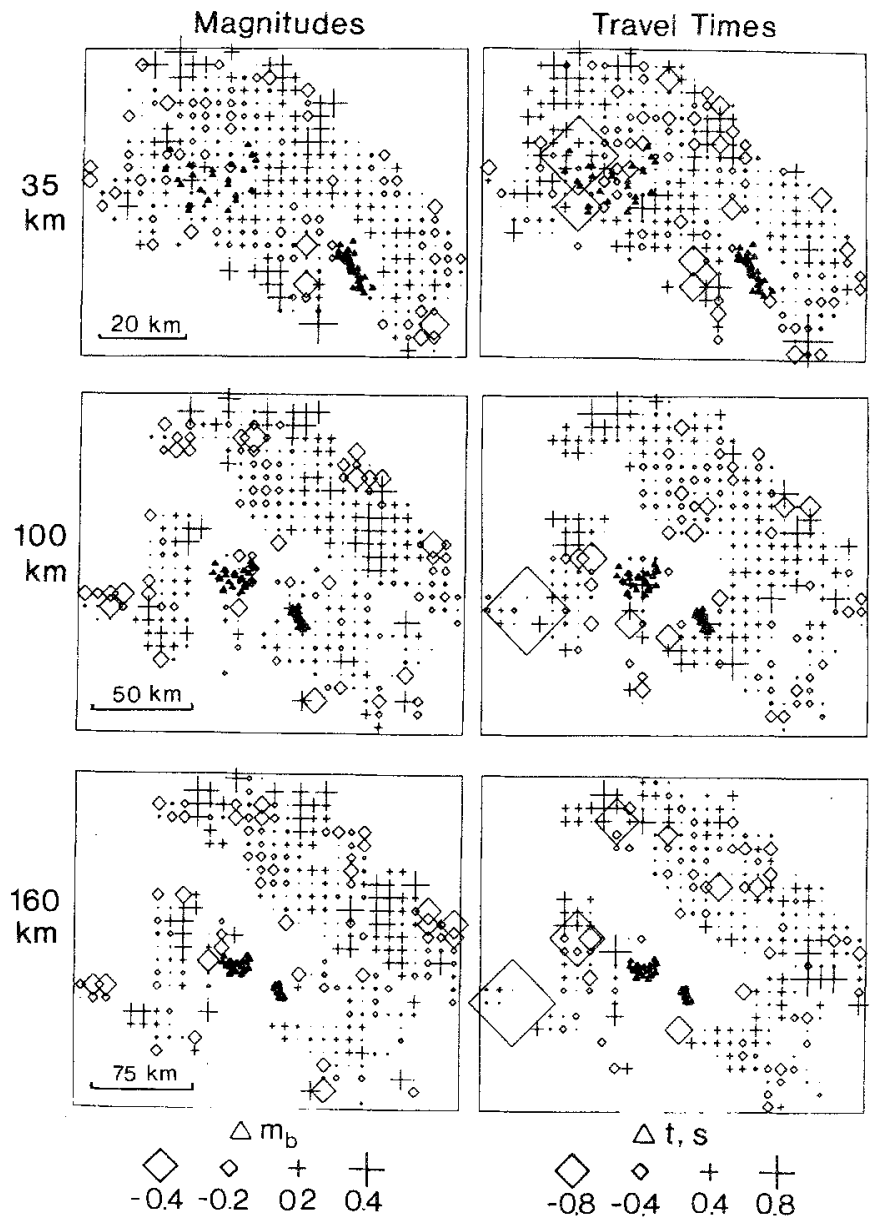

Figure 5

Bin-averaged back-projections of magnitude and travel-time anomalies with NTS station means removed to depths of $35 \mathrm{~km}, 100 \mathrm{~km}$, and $160 \mathrm{~km}$. 
and travel-time data sets. For the shallow depth, the images formed by the travel time and amplitude data are less coherent than the other depths, with mingled negative and positive values. This is due to the strong similarity of patterns for the explosions in a given test site: a structure as shallow as $35 \mathrm{~km}$ does not affect all the explosions similarly, leading to destructive interference in the back-projections. At $100 \mathrm{~km}$ depth, the images become more coherent, as indicated by the larger groupings of negative values, particularly in the NNE. Both the amplitudes and travel times form a northeast-trending low under the test site. The $160 \mathrm{~km}$ projection is fairly similar to the $100 \mathrm{~km}$ projection.
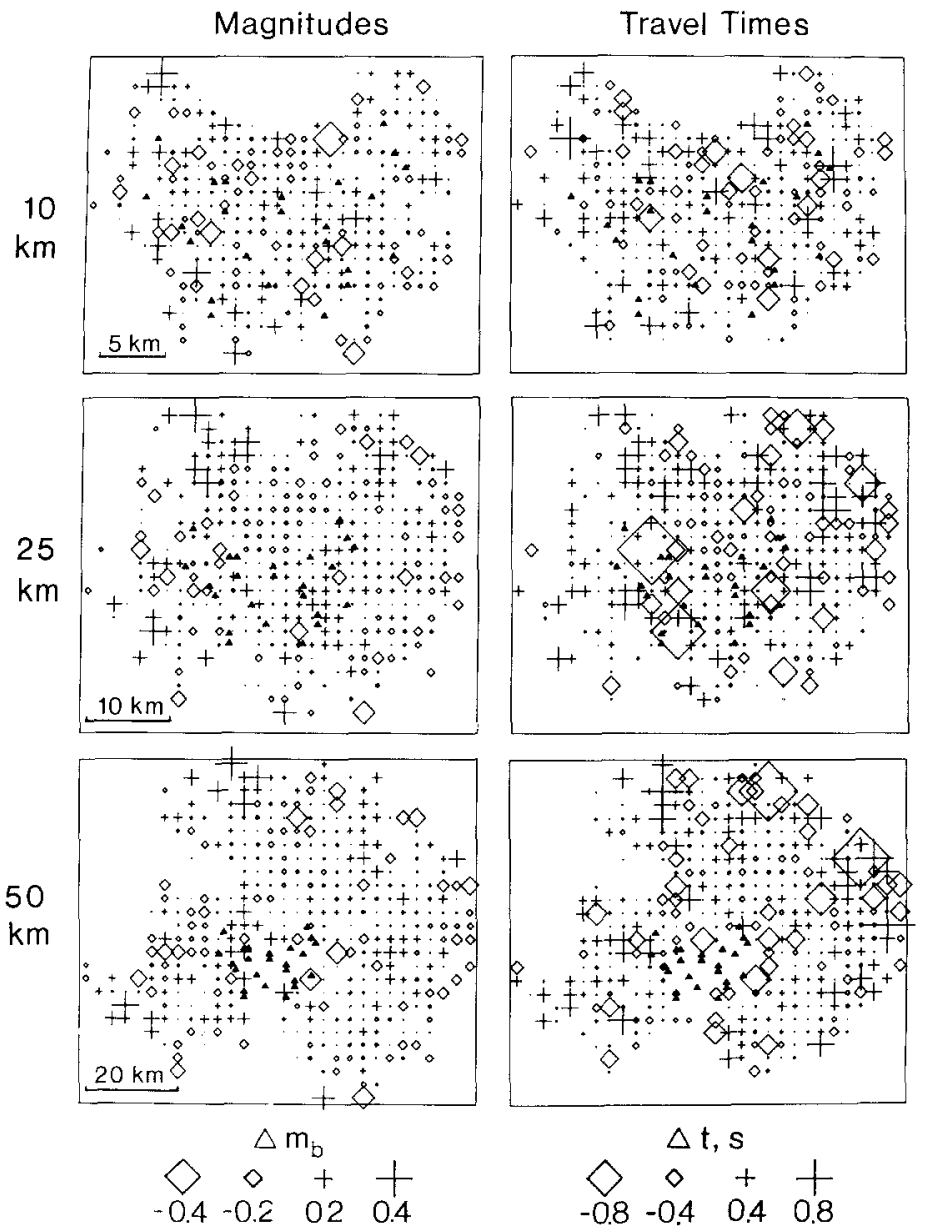

Figure 6

Bin-averaged back-projections of deviations from individual station means for the Pahute Mesa test site at depths of $10 \mathrm{~km}, 25 \mathrm{~km}$ and $50 \mathrm{~km}$. A coherent image of low values forms in both the magnitude and travel-time projections at $25 \mathrm{~km}$ depth. 
A similar procedure can be applied to the deviations from the subsite station mean for the amplitudes and travel times. In this case, both the event mean and individual station mean for a given test site are subtracted from each measurement. At large depths, the anomalies for a given station will fall in a single bin and average out to zero. Consequently, this component of the data set is most sensitive to very shallow structure.

The back-projections of the individual deviations from the station mean are shown for Pahute Mesa in Figure 6. The most shallow depth has a relatively incoherent pattern, indicating that no simple structure at this depth can explain much of the magnitude deviations. However, the $25 \mathrm{~km}$ deep projection has some very coherent images, particularly the large area of low amplitudes under the north-central part of the mesa. The $50 \mathrm{~km}$ deep projection is less coherent and has more bins with zero values, as expected. The corresponding projections for the Yucca Flat test site do not in general form coherent images. This result is in accord with the hypothesis of LYNNES and LAY (1988b) that the direct arrivals from Yucca Flat are heavily influenced by very shallow structure.

\section{Calculation of Time Delays from Amplitude Variations}

The criterion we use for choosing a projection depth is the correspondence of the travel-time projection with the travel times predicted by the amplitude projection, calculated using the wavefront curvature equation of HADDON and HUSEBYE (1978). The spatial distortion $(r(x, y))$ of a plane wavefront at an infinitely thin lens is given as

$$
r_{x x}+r_{y y}=\left[\left(A / A_{0}\right)^{2}-1\right] / h-h\left[r_{x x} r_{y y}-\left(r_{x y}\right)^{2}\right],
$$

where $A / A_{0}=$ relative amplitude, $h=$ depth of the lens, and subscripts indicate partial derivatives in Cartesian coordinates.

This equation is essentially a nonlinear version of Poisson's equation and can be solved for $r(x, y)$ given sufficiently smooth boundary conditions and amplitude variations by calculating the nonlinear terms on the right side of the equation from the previous iteration.

HADDON and HUSEBYE (1978) used observed travel-time residuals as boundary conditions at the grid edges in their study of amplitudes measured at the NORSAR array. However, for an irregular geometry such as the NTS explosion array, this choice of boundary conditions risks introducing biases based on a small subset of the travel times. Furthermore, this subset is the most poorly determined since its position on the fringe of the projection leads to a relatively low number of rays per bin and precludes a significant number of crossing rays. Consequently, we use zero boundary conditions at the edges of the grid, which are implemented by expanding 
both the travel time and amplitude grids by a few grid points and smoothly tapering each to zero at the grid edges.

The solution to equation (1) is obtained through a numerical solution to Poisson's equation (SweET, 1974; SwartzTrauber and SweET, 1975) on a rectangular grid. In order to satisfy this constraint, data-poor rows and columns were trimmed from the edges of the projections and the grid was expanded 2-4 points to implement the zero boundary conditions (Figure 7a). Values were then bilinearly interpolated at the grid points corresponding to bins with no data (Figure 7b).
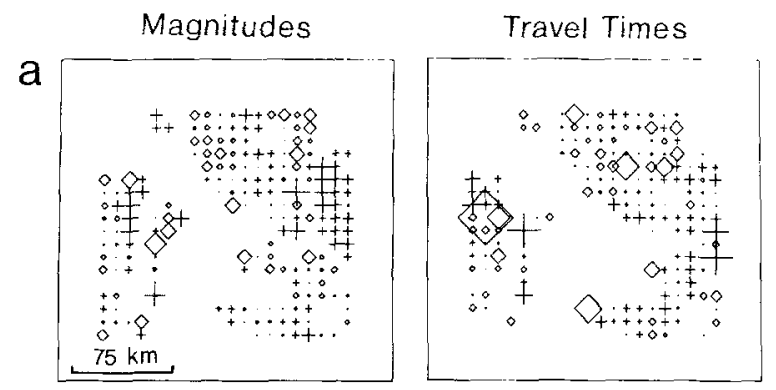

b
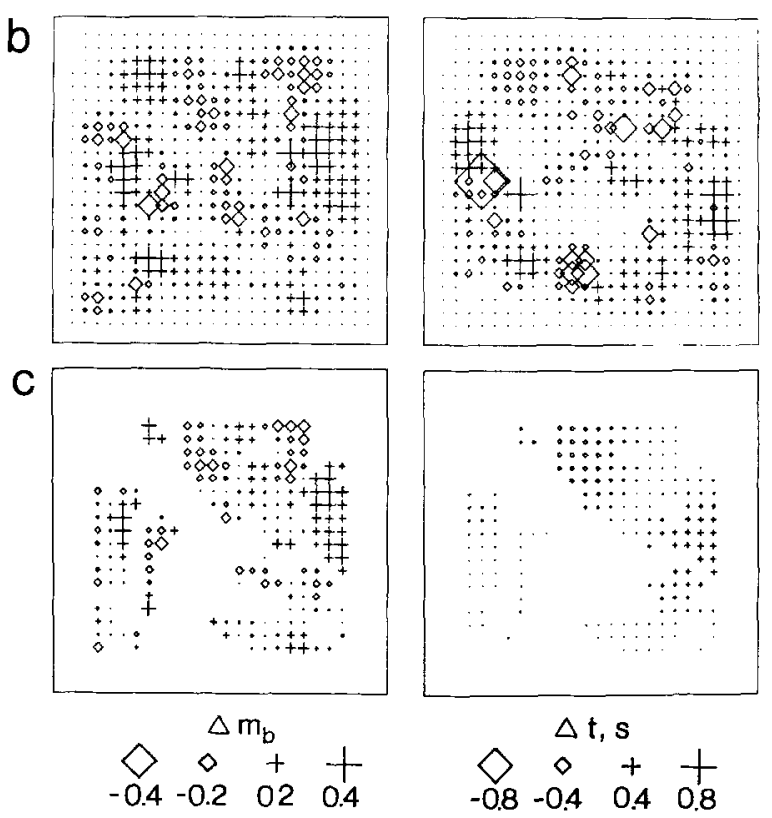

Figure 7

Examples of processing of bin-averaged surface to obtain a continuous, filtered, rectangular grid, for a depth of $160 \mathrm{~km}$. The original grids are shown in Figure 5 (bottom). The grid is cropped to remove data-poor columns and rows and expanded to allow the implementation of zero boundary conditions (a), interpolated to obtain a continuous rectangular grid (b), and filtered in doubly-transformed domain (c). The travel times are more heavily filtered than the amplitudes (see text). Only points which have data are shown in the last plot. 
A low-pass spatial filter was applied to both the amplitudes and travel times. The grids were transformed using a 2-dimensional FFT, the components with wavenumbers higher than a specified wavenumber were zeroed, and the grids were inverse transformed (Figure 7c). The travel-time surface was heavily filtered (components with wavelengths less than 6 grid points were removed) for two reasons. Firstly, the short-wavelength components are less reliable than the longwavelength components due to station effects and measurement uncertainty, and are less stable with respect to the bin-averaging procedure. Secondly, the double integration of the amplitudes in solving equation (1) produces a very smooth travel-time surface, meaning that the amplitudes cannot resolve short-wavelength features. Consequently, the amplitudes were only slightly filtered to remove shortwavelength noise before solving the equation. The spatial filter allows a comparison between features of similar scale length between the travel time and amplitudederived time delay surfaces. The comparison criterion is a cross-correlation coefficient of the filtered travel-time model with the amplitude-derived time delay model at the grid points whose corresponding bins contained data.

\section{Models Derived from Amplitude Variations}

The results for the thin lens models which had the best match between time delays predicted from amplitude variations and observed time delays are shown in Figure 8a. The depth for these models is $160 \mathrm{~km}$, and a correlation coefficient of 0.48 was obtained. The models appear most similar in the area of fast travel times trending northeast. This is also the area of the projection surface with the most data, and consequently the most robust features. If the observed and predicted travel-time surfaces are filtered more (wavelengths less than 10 grid points, or $100 \mathrm{~km}$ ) in order to compare the longer-wavelength features, the correlation coefficient increases to 0.79 (Figure $8 \mathrm{~b}$ ). The amplitude of the variation in the two models is also comparable. The high correlation in the long-wavelength components of predicted and observed travel times is a strong indication that most of the robust, long-wavelength amplitude variation arises from elastic focussing-defocussing. The correlation coefficient peaks at $160 \mathrm{~km}$, but decreases slowly with increasing depth. This is because the back-projections change slowly as the source array appears more like a point source. However, at depths below $160 \mathrm{~km}$, the amplitudes predict a much larger range in travel-time variation than indicated by the observed time delay surface. Therefore, we choose $160 \mathrm{~km}$ as the optimal projection depth.

The same procedure can be applied to the results of the deviations from the subsite station means. For Pahute Mesa, the best correlation of predicted and observed travel times is at a depth of $25 \mathrm{~km}$, which also had the most coherent images for the amplitude scatter (Figure 6). These correlate at a level of 0.43 , while the very-long-wavelength components correlate at a 0.71 level (Figure 9). However, the predicted range in travel times is only $0.05 \mathrm{~s}$ for the very-long- 


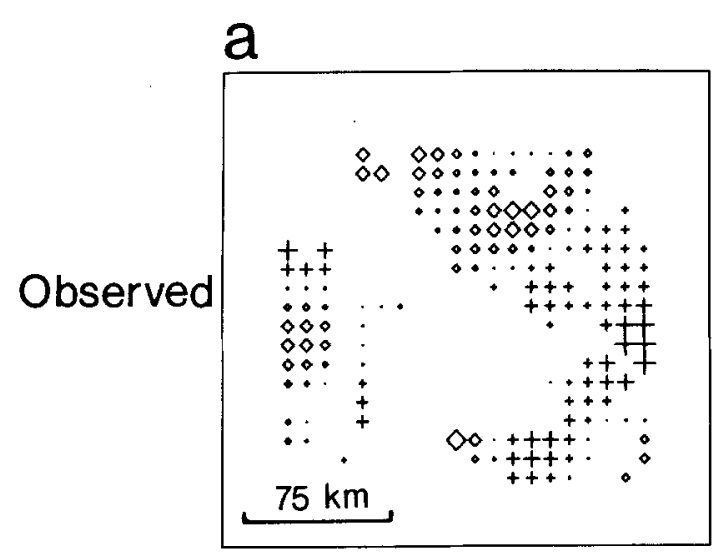

b
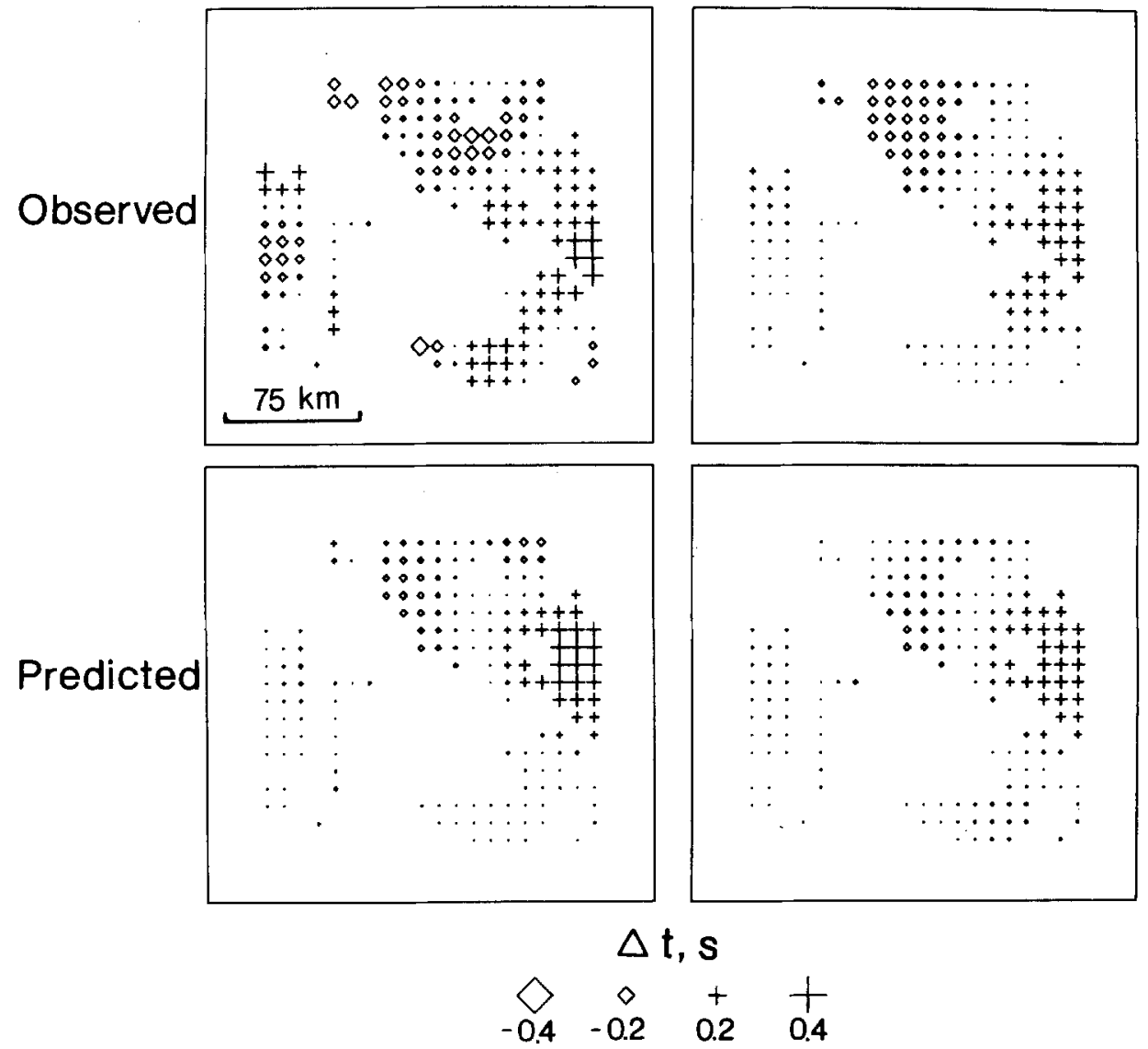

Figure 8

Thin lens results for $160 \mathrm{~km}$ depth, filtered to retain long-wavelength (a) and very-long-wavelength (b) components. The top plot plots are the filtered, observed travel times, and the bottom are the filtered travel times predicted from the magnitude variations.

wavelength component, whereas the observed range is $0.20 \mathrm{~s}$. This probably indicates that a single thin lens cannot predict both the amplitudes and travel times in this case, but rather a continuous distribution of velocity heterogeneity is needed to accumulate the appropriate travel-time anomalies. Nevertheless, it is instructive to see how far a discontinuity derived from a thin lens can go in producing the observed trends in amplitudes across the mesa. The same procedure was attempted for Yucca Flat, but the predicted travel-time variations were vanishingly small due to the failure of the back-projections to form coherent images.

The three-dimensionally velocity varying model is derived by simply mapping the 

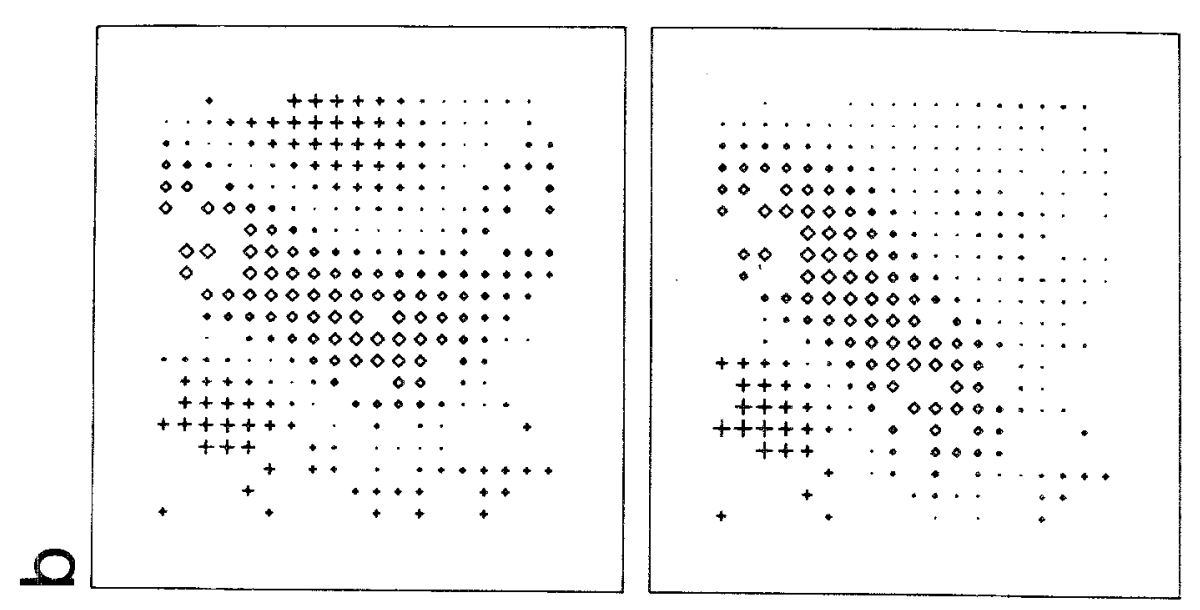

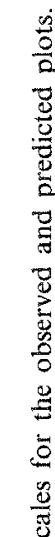
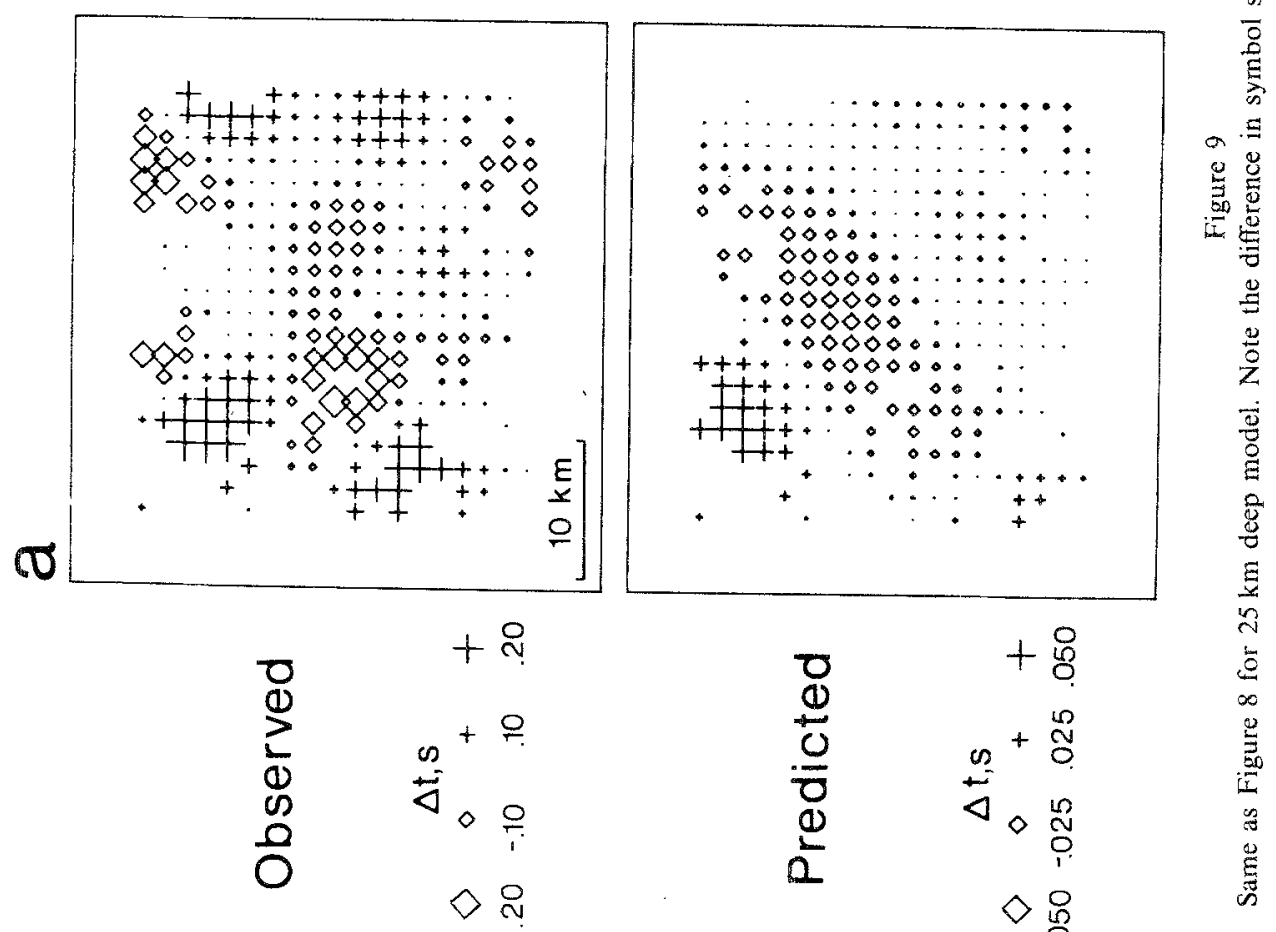
$160 \mathrm{~km}$

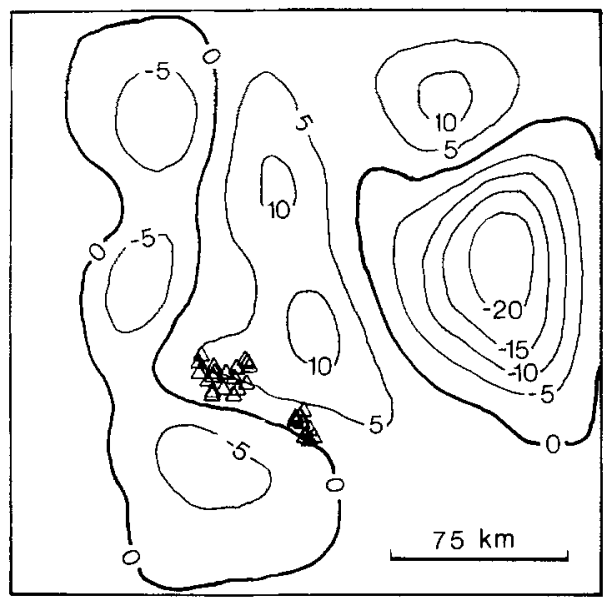

$25 \mathrm{~km}$

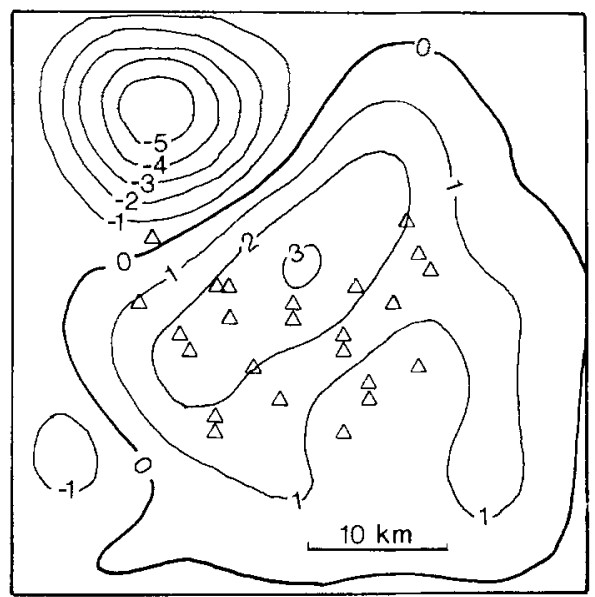

Figure 10

Contour plots (in $\mathrm{km}$ ) of the velocity discontinuity surfaces obtained from inversion of amplitudes. The deep $(160 \mathrm{~km})$ model obtained from intersite differences in magnitude patterns is shown on the left. The shallow $(25 \mathrm{~km})$ surface obtained from intrasite differences is shown on the right.

time delay surface into vertical deflections of a velocity discontinuity, using the equation

$$
\Delta z(x, y)=\Delta t /\left(1 / \alpha_{2}-1 / \alpha_{1}\right),
$$

where $\alpha_{1}$ and $\alpha_{2}$ are the $P$ wave velocities above and below the velocity discontinuity, respectively. The velocities used for the $160 \mathrm{~km}$ deep case are $7.70 \mathrm{~km} / \mathrm{s}$ and $8.25 \mathrm{~km} / \mathrm{s}$, chosen to correspond to the range of velocities in the low velocity zone of the T7 model. We model the shallow $(25 \mathrm{~km})$ case as a Conrad-type discontinuity with velocities of $6.4 \mathrm{~km} / \mathrm{s}$ and $7 \mathrm{~km} / \mathrm{s}$. The resultant surfaces are shown in Figure 10 .

Both surfaces are characterized by broad central highs, engendered by the low amplitudes in the center of the projections, with deep flanking lows. The $160 \mathrm{~km}$ deep surface has a range of about $30 \mathrm{~km}$, while the $25 \mathrm{~km}$ deep surface has a range of $8 \mathrm{~km}$. The discontinuities hypothesized for the purposes of the model construction are the base of the low-velocity zone and the base of the upper crust. As it is quite plausible that such boundaries would be rather irregular, the topography derived herein seems physically reasonable.

\section{Calculation of Kirchhoff-Helmholtz Synthetics}

HAdDon and Buchen (1981) and SCOTT and Helmberger (1985) have presented developments of the three-dimensional Kirchhoff-Helmholtz integral formulation for the transmitted case. The equation for a transmitted potential across 
a velocity discontinuity $\Sigma$ is:

$$
\varphi_{2}=1 /(4 \pi) \int_{\partial \Sigma} T f^{\prime}\left(t-\frac{r_{0}}{\alpha_{1}}-\frac{r}{\alpha_{2}}\right)\left(\cos \Theta_{2}+\cos \Theta_{1}\right) /\left(r_{0} r \alpha_{2}\right) d S,
$$

where $T$ is the acoustic plane wave transmission coefficient, $r_{0}$ is the source-surface element distance, $r$ is the surface element-receiver distance, $\Theta_{1}$ is the angle between the surface and the refracted wavefront, $\Theta_{2}$ is the angle between the surface-receiver vector and the normal to the surface, and $d S$ is an areal element (Figure 11). (This is modified from equation (13) in SCOTT and Helmberger, in which the second cosine term should be divided by $\alpha_{2}$, rather than $\alpha_{1}$.) The transmission coefficient is calculated for the local angle of incidence on the surface. If this angle exceeds the critical angle, the transmission coefficient is set equal to zero. A synthetic ramp response is calculated by simply summing step functions with the appropriate multipliers and time lags for each surface element. In order to obtain a teleseismic displacement seismogram, the resulting ramp response is numerically differentiated (Figure 12), and convolved with the second derivative of an explosion source potential, a Futterman operator with $t^{*}$ of 0.75 , and a short-period WWSSN instrument response. The source used for these seismograms is the modified Haskell source given by HELMBERGER and HADLEY (1981) as:

$$
\psi(t)=\psi_{0}\left[1-e^{-K t}\left(1+K t+(K t)^{2} / 2-B(K t)^{3}\right)\right] .
$$

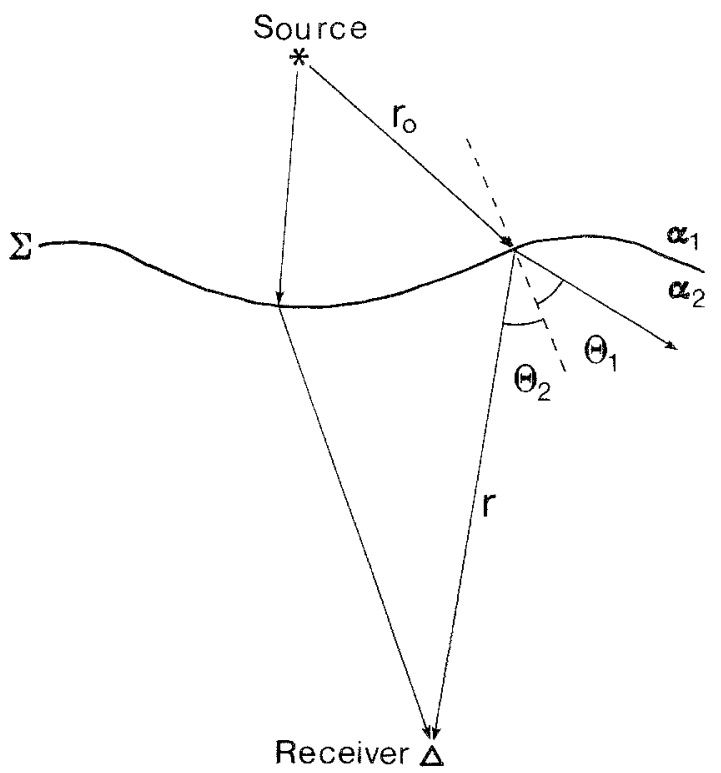

Figure 11

Geometry of synthetic seismogram computation. 


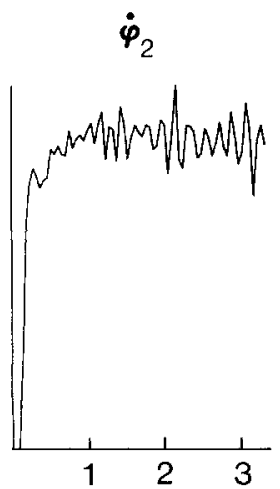

$\ddot{\mathrm{F}} * Q * \mid *(P+p P)$

$S$
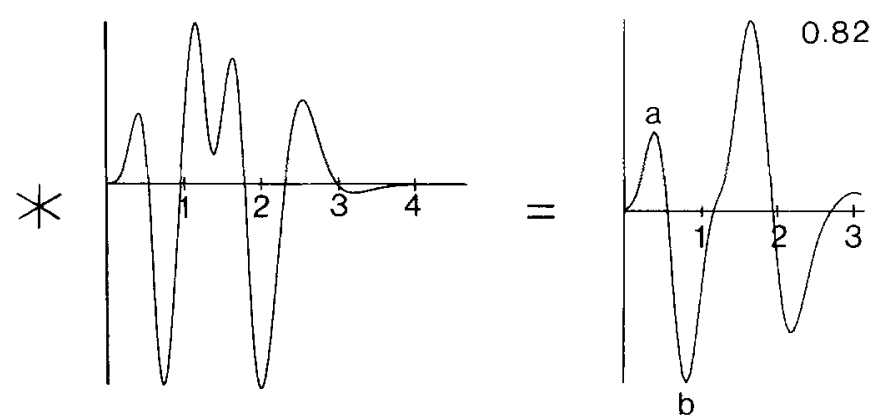

Figure 12

Example of synthetic calculation. On the left is a step (differentiated ramp) response for Pahute Mesa to UME for the deep model. This is convolved with a function containing the source, instrument, free-surface and attenuation $\left(t^{*}=0.75\right)$ responses (center). On the right is the final seismogram with the $a b$ amplitude relative to the flat layer case indicated in the upper right.

The values of $K$ and $B$ used for the seismograms are 8 and 1, respectively. A $p P$ phase with a time lag of $0.9 \mathrm{~s}$ and reflection coefficient of -1 is also added, but does not affect the $a b$ (first peak to first trough) part of the waveform.

The seismograms are calculated for two welded half-spaces, using acoustic transmission coefficients. The receivers are located $20,000 \mathrm{~km}$ below the interface, corresponding to the geometric spreading at an epicentral distance of $60^{\circ}$ in the real earth. The $x$ and $y$ coordinates are chosen so that the intersection of the geometric ray with a flat interface coincides with $x-y$ coordinates in the back-projections for a given source-station geometry. Synthetic seismograms are also computed for the flat-interface case. The $a b$ amplitudes are calculated for the model synthetics and divided by the $a b$ amplitudes for the flat-layer synthetics. In all, the computation of the synthetics is fairly easy and quick, facilitating the testing of a large number of different models for many source-station pairs.

\section{Synthetic Tests of Models}

For the $160 \mathrm{~km}$ deep discontinuity, synthetic seismograms were calculated for 56 teleseismic stations from sources in the center of the Pahute Mesa and Yucca Flat sites. The differences in the Pahute Mesa and Yucca Flat log amplitudes are shown for each station in Figure 13, along with the differences in the observed Pahute Mesa and Yucca Flat station mean magnitudes ${ }_{\mathrm{PM}} S_{i}-{ }_{\mathrm{YF}} S_{i}$ ). The patterns are strikingly similar, differing only in strength. Even fairly subtle details in the observed pattern are matched in the synthetics, such as the trend in the closer stations from relatively low magnitudes to the north for Pahute Mesa relative to Yucca Flat, to high magnitudes in the NNE, low magnitudes in the NE, and high 


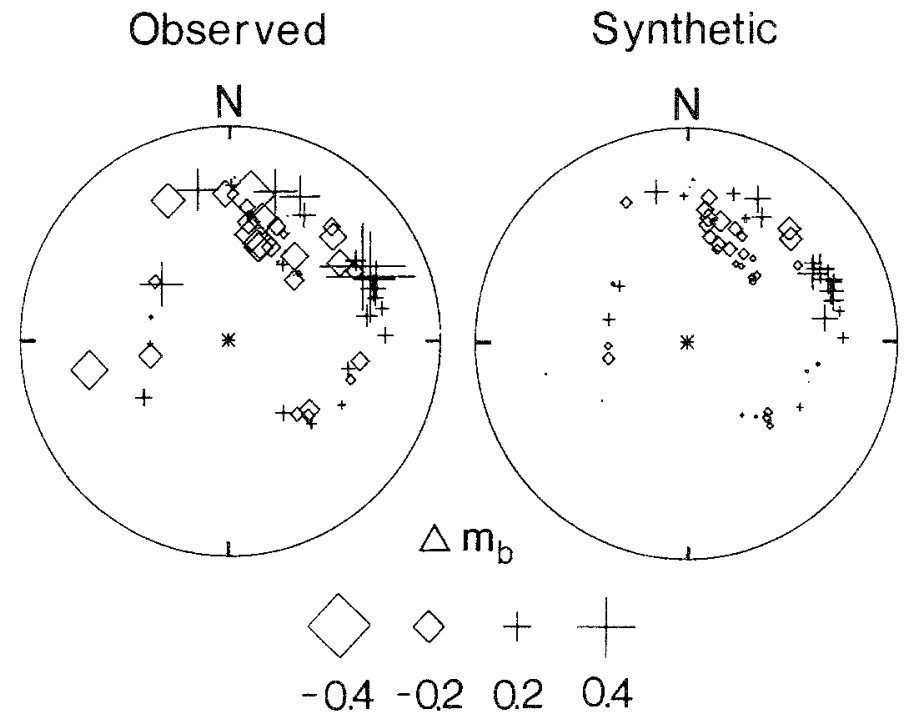

Figure 13

Comparison of synthetic log-amplitude variations with observed variations in $m_{b}$. The equal-area plot on the left shows the observed station average $m_{b}$ values for Yucca Flat differenced from the corresponding station means for Pahute Mesa. The equal-area plot on the right shows synthetic log-amplitude variations of Yucca Flat explosions differenced from those of Pahute Mesa.

magnitudes in the ENE and east. Thus, the imaging of three-dimensionally varying structure from the amplitude variations appears to be successful in predicting much of the amplitude behavior. Of course, it cannot be expected to match the full range of variation because the back-projection utilizes destructive interference to mask out anomalies that are not identified with that particular projection depth. Thus, the technique is intrinsically conservative.

The patterns of travel-time residuals also are strikingly similar for both the synthetic and observed seismograms (Figure 14). Again, the range of variation is not matched by the model, due to the conservative nature of the procedure. Nevertheless, it is encouraging that the model derived from amplitude variations qualitatively predicts the observed travel-time variations as well. This agreement also indicates that the choice of zero boundary conditions in the wavefront curvature equation does not introduce any significant artifacts.

The Kirchhoff-Helmholtz synthetics for the shallow model are somewhat more difficult to construct. Because of the shallow depth and short scale lengths of the model, the local angle of incidence exceeds the critical angle for part of the surface (Figure 15a) for many of the source-station geometries. In fact, this effect is a primary contributor to the variations in waveform and amplitude for the different structures tested by SCOTT and HeLmberger (1985). For the model tested here, the masking effect is particularly prevalent on the steep transition from the high to 


\section{Observed}

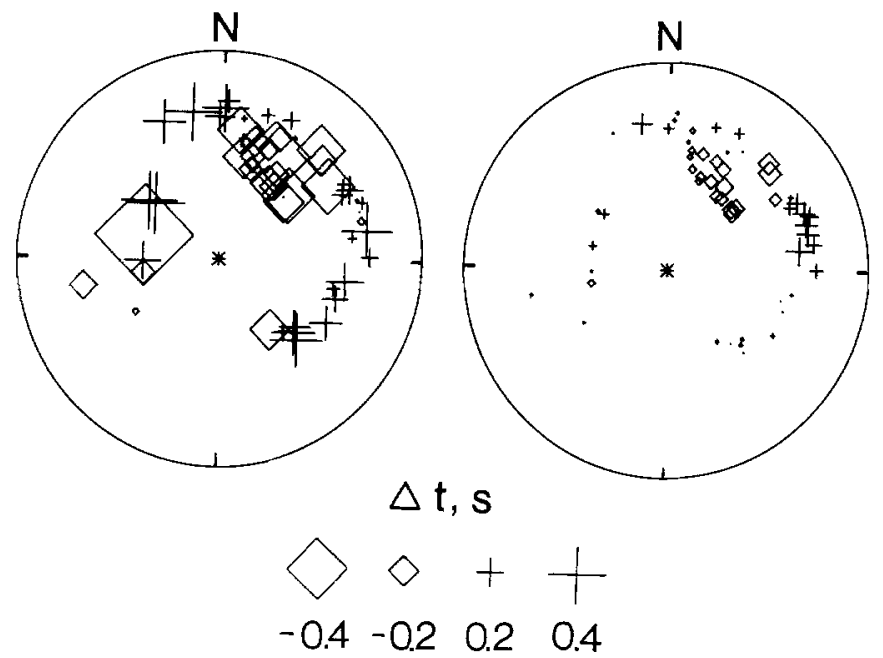

Synthetic

Figure 14

Same as Figure 13, for travel times.

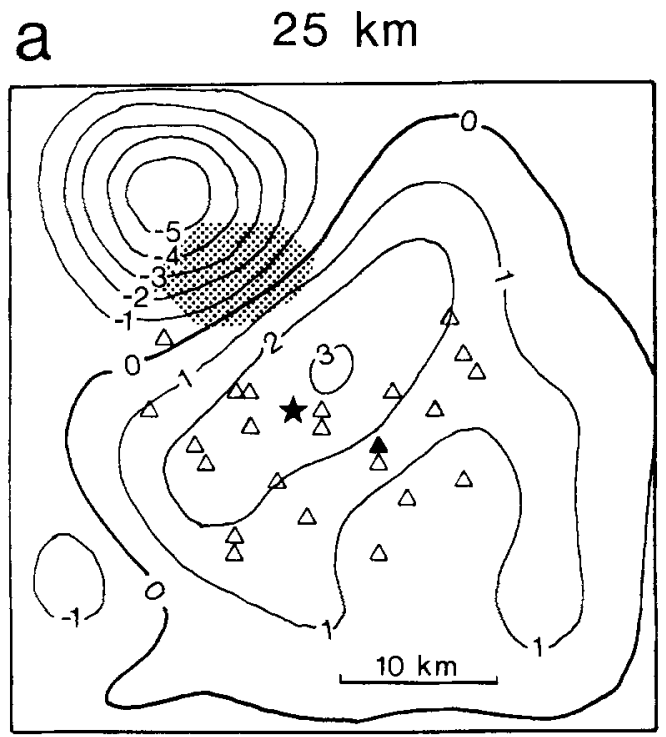

b
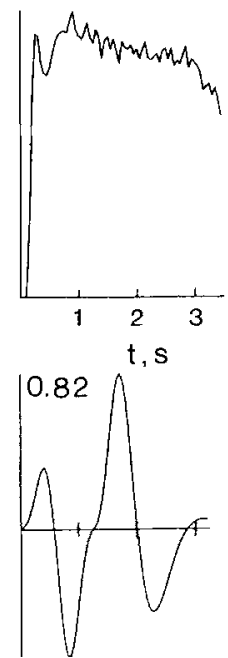

C
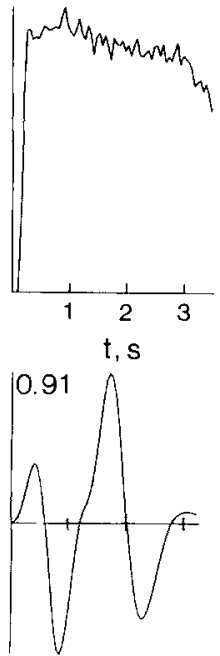

Figure 15

The $25 \mathrm{~km}$ deep model is shown in (a), the stippled area indicating where the local angle of incidence exceeds the critical angle for the event CAMEMBERT (filled triangle) to station MAT. The geometric arrival intersects the surface at the star. The "masked" portion of the surface leads to a truncation in the first second of the step response (b). This is smoothed out by assigning the masked elements the amplitude factors of adjacent elements (c) in order to evaluate the magnitude of this effect. The numbers in (b) and (c) indicate $a b$ amplitudes relative to the flat-layer case. 
the low on the surface. Since such surface elements are assigned a transmission coefficient of zero in the computation of the seismograms, this results in a somewhat artificial truncation effect in the very early part of the waveform (Figure 15b). These truncation effects can produce large variations in the $a b$ amplitudes. In order to assess the general magnitude of these effects, the synthetics were recomputed by assigning supercritical elements the amplitude factor of adjacent elements. This has the effect of generally smoothing out the effect of the truncation (Figure 15c). Stations for which the $a b$ amplitudes changed more than a few percent, which were primarily the stations to the west such as MAT, were excluded from the analysis. However, the actual $a b$ amplitudes used herein are those calculated by masking out critical and supercritical elements.

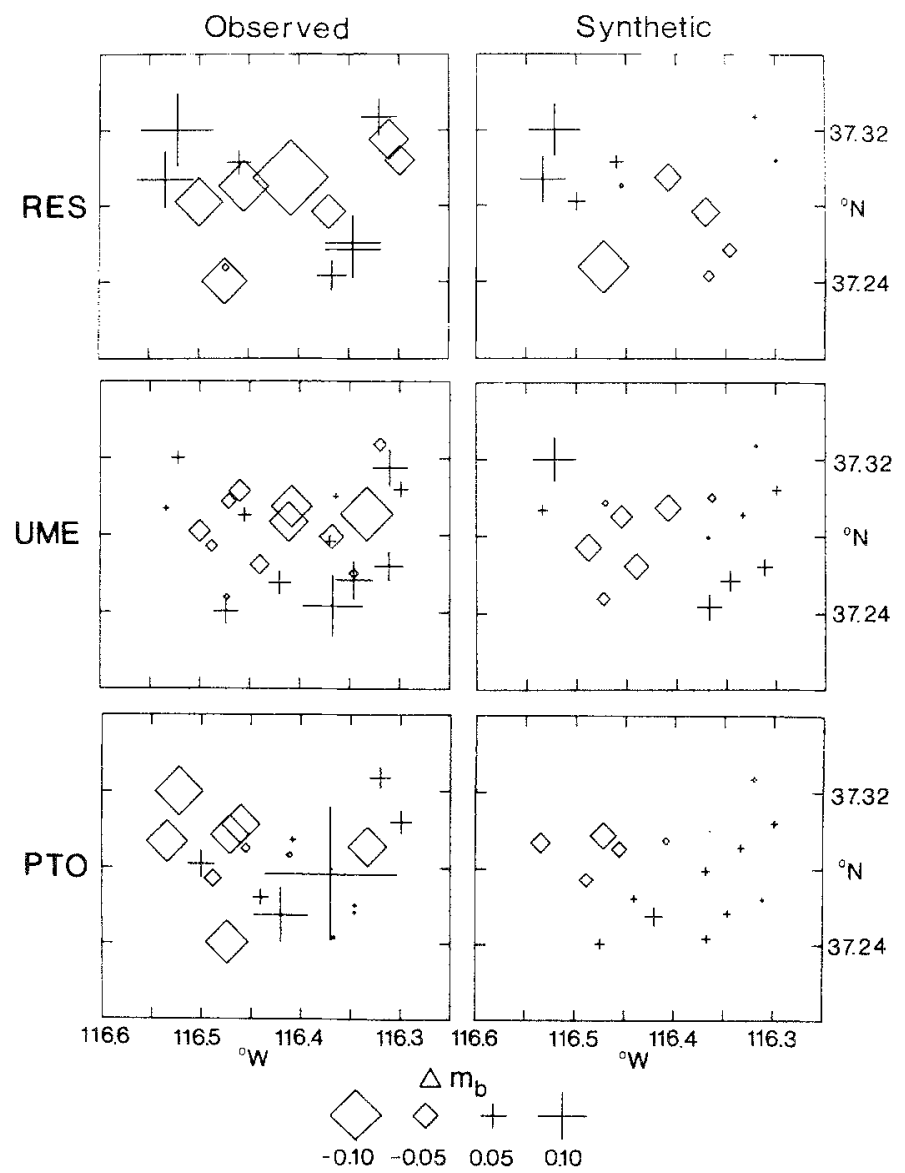

Figure 16

(a) Variations in synthetic log amplitudes with position in Pahute Mesa, calculated for Resolute Bay, Canada (RES), Umea, Sweden (UME), and Porto, Portugal (PTO). (b) Observed variations in $m_{b}$, obtained by averaging nearby stations with those for which the synthetics were calculated. 
The variation of $\log$ amplitude with position in the test site for three stations are shown in Figure 16. Since the corresponding variations in observed $m_{b}$ values are highly contaminated by incoherent measurement errors, the deviations from the station means for nearby stations were averaged in for each explosion for the comparison (Figure 16). As with the deep model, the synthetic log amplitudes have the correct sense of variation, but underpredict the amplitudes. However, this qualitative correlation is quite important, because it implies that the "scatter" about the station means can in fact be partially interpreted in a deterministic framework. This is supported by the coherent variations of observed $m_{b}$ deviations within the mesa for each group of stations.

\section{Discussion}

It is interesting to compare the models derived from amplitudes in this study with those derived from travel times. A vertical cross-section through the Minster et al. (1981) velocity structure of NTS, plotted as contours, and the TAYLOR (1983) velocity structure of NTS, plotted as symbols, is shown in Figure 17, with cross-sections of the two velocity discontinuity models derived in this study from amplitudes superimposed. The two travel-time structures are reasonably similar, although the TAYLOR (1983) structure terminates more shallowly and has much larger velocity variations. The amplitude-derived structure at $25 \mathrm{~km}$ is qualitatively similar to both, with an upwarp in the high-velocity material closely corresponding to fast velocity regions in both travel-time models. The deep amplitude model is more difficult to compare since it is located deeper than either of the travel-time model parameterizations. However, if the high-velocity regions in the travel-time models are extended down along the raypaths to the stations to the NNE, they would intersect an upwarp of the high-velocity material.

One shortcoming of the procedure used in this study for deriving three-dimensionally varying models from amplitudes appears to be a systematic underprediction of the range in amplitude variations. This is a common problem in attempts to predict amplitudes in an elastic framework. As noted earlier, the structures derived from travel times by THOMSON and GUBBINS (1982) for NORSAR and by MINSTER et al. (1981) for NTS both underpredict amplitude variations to a varying degree. The structure derived by TAYLOR (1983) for NTS does predict amplitude variations of the same order as the data (CORMIER, 1987), but this is the result of very large velocity differences over short distances, ranging from $16 \%$ over $14 \mathrm{~km}$ in the most shallow layer to $5 \%$ over $20 \mathrm{~km}$ in the deepest layer.

In theory, a structure derived from the amplitudes should be better able to predict the range of amplitude variation. THOMSON's (1983) models for NORSAR derived using a ray-theoretical amplitude inversion predict the observed amplitude variation better than the travel-time model A2 (ThOMSON and GubBins, 1982), 


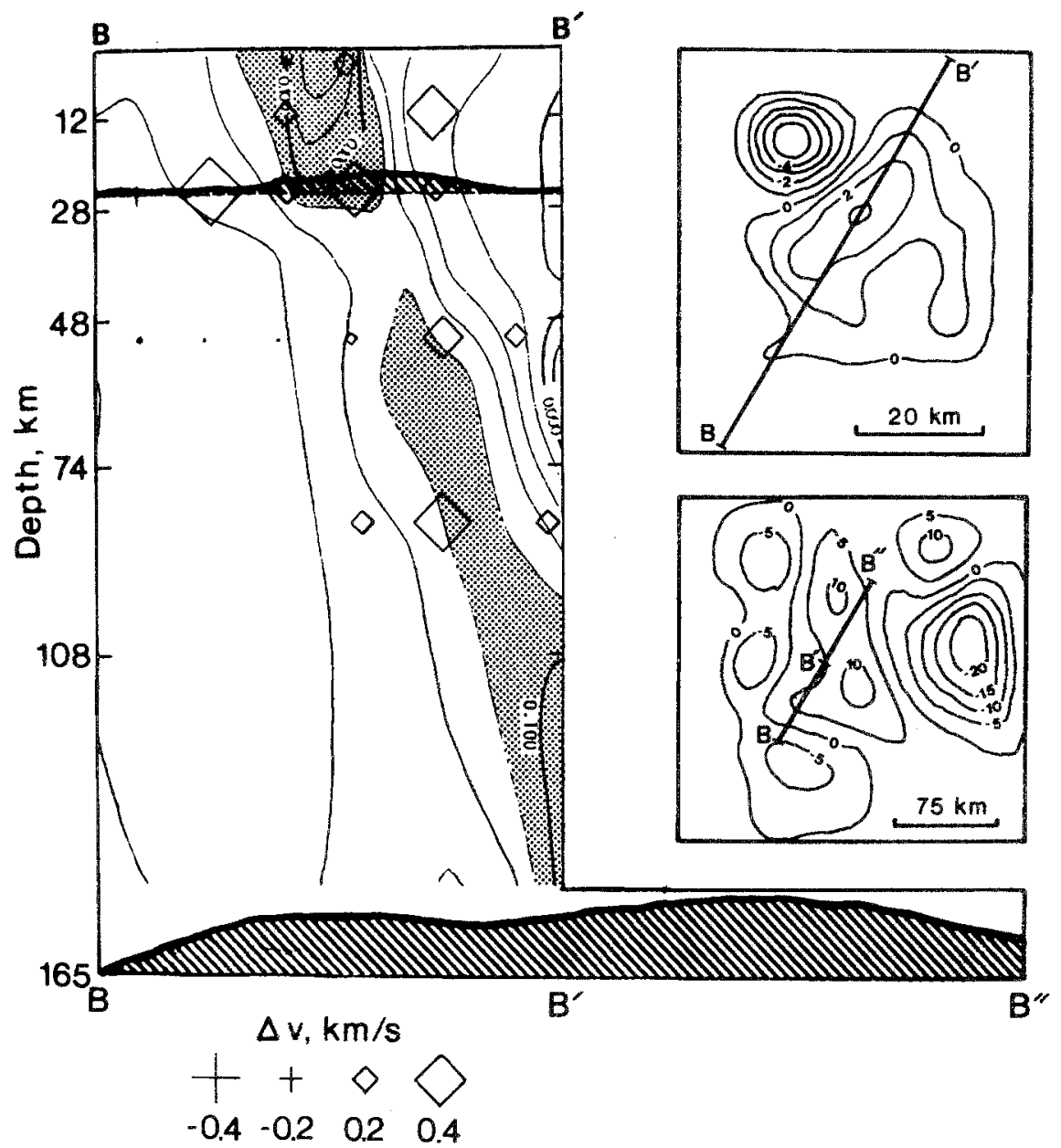

Figure 17

Comparison of discontinuity models with block inversion models derived from travel times by other authors. The figure on the left is a modification of Figure 4.13b of MinsTer et al. (1981), which is a vertical cross-section through their model, represented by the velocity contours. Symbols indicate the velocity perturbations in the blocks of TAYLOR's (1983) model that the cross-section intersects. The thick black lines are the equivalent cross-section through the shallow $(25 \mathrm{~km})$ velocity discontinuity model and an extended cross-section through the deep $(160 \mathrm{~km})$ model. The locations of the cross-sections are plotted on contour maps of the surfaces on the right. High velocity regions or extensions thereof in the block travel-time models correspond to upwarps of high velocity material in the amplitude-derived discontinuity models.

even though the latter model has stronger velocity variations. For the case of the procedure presented in this paper, the main factor contributing to the underprediction of the amplitudes seems to be the parameterization of only a single surface for a given model. The destructive interference in the back-projections ensures that only part of the available information in the amplitudes is being utilized. We have 
attempted to circumvent this by examining both the regionally demeaned anomalies (for the deep models) and the deviations from the individual station means (for the shallow models). However, it may be possible to simultaneously back-project anomalies to two or more surfaces, i.e., tomographically image the amplitude data. This should retain more of the amplitude information, resulting in more accurate models.

A second shortcoming of the technique is the tendency to underpredict the traveltime variations (which are first-order effects of velocity perturbations) even more than the amplitude variations. As noted earlier, however, MINSTER et al.'s (1981) structure, which predicts the full range of travel times, predicts almost no amplitude variation. Thus, additional velocity anomalies may be added to the discontinuity structure to produce the full travel-time variation, so long as they are distributed over large enough spatial scales that they introduce negligible velocity gradients.

It should also be noted that we have attempted to explain only the intrasite and intersite differences. However, it is apparent from the similarity of the Yucca Flat and Pahute Mesa azimuthal patterns that the two subsites share a large common component in both amplitude and travel-time variations (Figure 2), with low magnitudes and fast travel times to the northeast. This component is as much as 0.2 units for the magnitudes and $1.0 \mathrm{~s}$ for the travel times. The relatively small ratio of amplitude to travel-time anomaly indicates very broad scale lengths, and this, coupled with the fact that both subsites must be affected similarly, indicates a deep $(>400 \mathrm{~km})$ source for the common patterns.

\section{Conclusions}

We have used a combination of thin lens projections, calculation of time delays from amplitudes using the wavefront curvature equation, and mapping time delays into a warped velocity discontinuity to image three-dimensionally varying structure from amplitude data. Synthetic seismograms can be easily computed for these discontinuities using the Kirchhoff-Helmholtz technique. A comparison of observed and synthetic magnitude anomalies indicates that the coherent intersite and intrasite differences in magnitudes from NTS explosions can be partially explained by warped velocity discontinuities $25 \mathrm{~km}$ and $160 \mathrm{~km}$ beneath the source array.

\section{Acknowledgements}

We thank two anonymous reviewers for helpful comments on this manuscript.

This research was supported by the Sloan Foundation, a Shell Faculty Career Initiation Grant, and the Defense Advanced Research Projects Agency, and was monitored by the Air Force Geophysics Laboratory under Contract F19628-87$\mathrm{K}-0010$. 


\section{REFERENCES}

Burdick, L. J., and Helmberger, D. V. (1978), The Upper Mantle P Velocity Structure of the Western United States, J. Geophys. Res. 83, 1699-1712.

Burger, R. W., LAY, T., and Burdick, L. J. (1986), Estimating the Relative Yields of Novaya Zemlya Tests by Waveform Intercorrelation, Geophys. J. R. Astr. Soc. 87, 775-800.

Butler, R. (1983), P Wave Travel Time and Amplitude in Western North America, Nature 306, 677-678.

Butler, R. (1984), Azimuth, Energy, $Q$, and Temperature: Variations on $P$ Wave Amplitudes in the United States, Reviews of Geophysics and Space Physics 22, 1-36.

ChAng, A. C., and von SEgGern, D. H. (1980), A Study of Amplitude Anomaly and $m_{b}$ Bias at LASA Subarrays, J. Geophys. Res. 85, 4811-4828.

CORMIER, V. F. (1987), Focusing and Defocusing of Teleseismic P Waves by Known 3-d Structure Beneath Pahute Mesa, Nevada Test Site, Bull. Seism. Soc. Am. 77, 1688-1703.

HADDON, R. A. W., and BUCHEN, P. W. (1981), Use of Kirchhoff's Formula for Body Wave Calculations in the Earth, Geophys. J. R. Astr. Soc. 67, 587-598.

HAdDon, R. A. W., and Buchen, P. W. (1981), Joint Interpretation of $P$ Wave Time and Amplitude Anomalies in Terms of Lithospheric Heterogeneities, Geophys. J. R. Astr. Soc. 55, 19-43.

Helmberger, D. V., and Hadley, D. M. (1981), Seismic Source Functions and Attenuation from Local and Teleseismic Observations of the NTS Events JORUM and HANDLEY, Bull. Seismol. Soc. Am. 71, $51-67$.

LAy, T., Lynnes, C. S., and WelC, J. (1986), Analysis of Teleseismic P Wave Amplitude and Coda Variations for Underground Explosions at U. S. and Soviet Test Sites, Scientific Report AFGL-TR-860038, University of Michigan, Ann Arbor, Michigan.

Lay, T., Wallace, T. C., and Helmberger, D. V. (1984), The Effects of Tectonic Release on Short-period P Waves from NTS Explosions, Bull. Seismol. Soc. Am. 74, 819-842.

LyNNES, C. S., and LAY, T. (1988a), Analysis of Amplitude and Travel Time Anomalies for Short-period $P$ Waves from NTS Explosions, Geophys. J. R. Astr. Soc. 92, 431-443.

LYNNES, C. S., and LAY, T. (1988b), Observations of teleseismic $P$ wave coda for underground explosions, In Scattering and Attenuation of Seismic Waves, Pure Appl. Geophys. 128, 231-249.

Minster, J. B., SAvino, J. M., Rodi, W. L., Jordan, T. H., and Masso, J. F. (1981), Three-dimensional Velocity Structure of the Crust and Upper Mantle Beneath the Nevada Test Site, Final Technical Report $S S-R-81 \cdot 5138$, Science, Systems and Software, La Jolla, California.

Scort, P., and Helmberger, D. V. (1985), Applications of the Transmitted Kirchhoff-Helmholtz Method to Transmitted Body Wave and Possible Structural Effects at NTS, Bull. Seismol. Soc. Am. 75, $131-156$.

SPENCE, W. (1974), P Wave Residual Differences and Inferences on an Upper Mantle Source for the Silent Canyon Volcanic Center, Southern Great Basin, Nevada, Geophys. J. R. Astr. Soc. 38, 505-523.

Swartztrauber, P. N., and SwEet, R. A. (1975), Efficient FORTRAN Subprograms for the Solution of Elliptic Partial Differential Equations, NCAR Technical Note NCAR-TN/IA-109.

SweET, R. A. (1974), A Generalized Cyclic Reduction Algorithm, SIAM J. Numer. Anal. 11, 506-520.

TAYLOR, S. R. (1983), Three-dimensional Crust and Upper Mantle Structure at the Nevada Test Site, J. Geophys. Res. 88, 2220-2232.

THOMSON, C. (1983), Ray-theoretical Amplitude Inversion for Laterally Varying Velocity Structure Below NORSAR, Geophys. J. R. Astr. Soc. 74, 525-558.

THOMson, C. J., and GuBBins, D. (1982), Three-dimensional Lithospheric Modelling at NORSAR: Linearity of the Method and Amplitude Variation from the Anomalies, Geophys. J. R. Astr. Soc. 7I, $1-36$.

(Received May 20, 1987, revised December 25, 1987, accepted January 8, 1988). 